\title{
Study of Gender Difference in Emotional Maturity among Adolescents
}

\author{
Seema Bajaj and Sukhjot Nancy
}

\begin{abstract}
Aim: The aim of the study was to observe gender difference in emotional maturity among adolescents. Materials and Method: Samples of 200 adults (100 males and 100 females) were selected from Bassi Pathana, District Fatehgarh Sahib, Punjab. For data collection, Emotional Maturity Scale by Dr. Yashvir Singh and Dr. Mahesh Bhargava was used. Results: No significant difference exists between mean scores of the variable of emotional maturity of male and female adolescents. Conclusion: It was concluded that gender does not play a significant role in determining the emotional maturity among adolescents.
\end{abstract}

\author{
Seema Bajaj \\ Assistant Professor \\ Master Tara Singh Memorial College for Women \\ Ludhiana (Punjab) India \\ Email: seemabajaj74in@yahoo.co.in \\ Sukhjot Nancy \\ Clinical Psychologist \\ Amar Neuropsychiatry Clinic, Sirhind \\ District Fatehgarh Sahib (Punjab) India
}

\section{Key Words: Emotional Maturity, Adolescents, Gender Difference}

DOI: $10.18376 /$ jesp/2019/v15/i1/111315

\section{Introduction}

Emotional Maturity is a personality trait, the result of emotional development and the display of emotion appropriate to one's chronological age. It usually reflects increased emotional adjustment and emotional stability and the attainment of emotional self-regulation. Emotional Maturity is the ability to differentiate and properly identify one's emotions while granting yourself the freedom to experience whatever emotion is appropriate to a given situation. Not all adolescents, by any means go through a period of exaggerated storm and stress. True, most of them do experience emotional instability from time to time, which is logical consequence of the necessity of making adjustments to new patterns of behaviour and to new social expectations. According to Seoul (1951) "If the emotional development of the individual is relatively complete, his adaptability is high, his regressive tendencies are low and his vulnerability is minimal". According to Walter D. Smitson (1974) "Emotional maturity is a process in which the personality is continuously striving for greater sense of emotional health, both intra-psychically and intra-personally". It is possible to become more emotionally mature by doing things for others, expanding the social circle and being honest with oneself and finding something bigger and better to focus. Anand et. al.,(2014) analysed impact of different factors on emotional maturity of adolescents of co educational school. Their sample consisted of 220 students from the coeducational English medium school of Kanpur District (110 boys and 110 girls). They collected the sample by using multistage random sampling technique. Self designed socio-demographic questionnaire was used to study the socio-demographic characteristics of respondents and they used Emotional maturity scale of Dr.Yashvir Singh and Dr. Mahesh Bhargava. From the results of their study, it was concluded that family, peer group, school and society plays an important role in the emotional stability of adolescents. Dutta and Chetia (2014) studied on Emotional Maturity of Secondary School Students in Lakhimpur and Sonitpur Districts of Assam and they had a taken a sample of 1000 students (500 boys and 500 girls).They used descriptive survey method and Emotional Maturity Scale of M. Bhargava and Y. Singh was 


\section{Journal of Exercise Science \& Physiotherapy Vol. 15 No. 1 (January to June) 2019}

ISSN: 0973-2020 (Print) I I OR Impact Factor $=6.502 \quad$ ISSN: 2454-6089 (Online)

used. The findings of their study reported that there was no significant difference in various areas of Emotional Maturity of government and private school students, no significant difference in the emotional maturity of boys and girl school students and no significant difference between the emotional maturity level of rural and urban area secondary school students of both districts of Assam. Gunasekar and Pugalenthi (2015) conducted a study on emotional maturity and academic achievement of students at secondary level. In their study, a sample of 100 students (50 boys and 50 girls) were taken. Emotional Maturity scale was used. For academic achievement marks obtained in $10^{\text {th }}$ classs of state board were used. The findings of their study revealed that there is no significant difference between boys and girls of secondary level student on emotional maturity and academic achievement. Duhan et. al., (2017) revealed emotional maturity of adolescents in relation to their gender. For their study, a sample of $11^{\text {th }}$ standard students was taken. Non- significant and negative correlation existed between age and sex with emotional maturity aspects which shows that with increase in age, emotional instability regression, social maladjustment, personality disintegration and lack of independence will go on decreasing.

\section{Materials and Methods}

The present study was conducted on 200 adults (100 males and 100 females) were selected from Bassi Pathana, District Fatehgarh Sahib, Punjab. For data collection, Emotional Maturity Scale by Dr. Yashvir Singh and Dr. Mahesh Bhargava was used.

\section{Results and Discussion}

The variable of Emotional Maturity among male adolescents was tested for normalcy. Table 1 shows that the values of mean and median of the male scores of adolescents on the variable of Emotional Maturity as 106.96 and 107.50 respectively which are quite proximate to each other. The values of skewness and kurtosis in case of male adolescents are 0.19 and -0.12 respectively showing the distribution as positively skewed and platykurtic. But these distortions are quite small. Therefore the distributions can be taken as normal.

Table 1. Mean, Median, Standard Deviation, Skewness and Kurtosis of scores of Male Adolescents on the variable of Emotional maturity $(N=100)$

\begin{tabular}{|c|c|c|c|c|c|}
\hline Group & Mean & Median & S.D. & Skewness & Kurtosis \\
\hline Male Adolescents & 106.96 & 107.50 & 20.49 & 0.19 & -0.12 \\
\hline
\end{tabular}

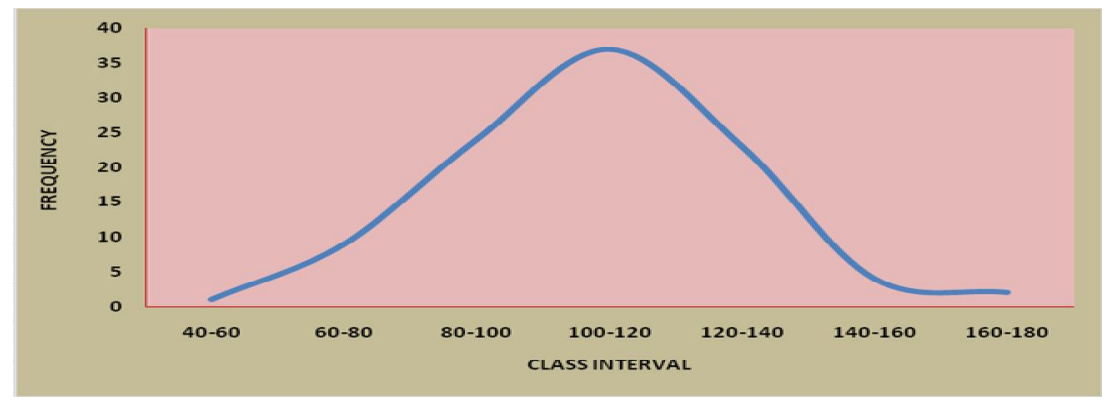

Figure 1. Frequency Polygon of scores of Male Adolescents on the variable of Emotional Maturity ( $\mathrm{N}=\mathbf{1 0 0}$ ) 
Journal of Exercise Science \& Physiotherapy Vol. 15 No. 1 (January to June) 2019

ISSN: 0973-2020 (Print) I I OR Impact Factor =6.502 ISSN: 2454-6089 (Online)

Table 2. Mean, Median, Standard Deviation, Skewness and Kurtosis of scores of Female Adolescents on the variable of Emotional Maturity $(\mathrm{N}=100)$

\begin{tabular}{|c|c|c|c|c|c|}
\hline Group & Mean & Median & S.D. & Skewness & Kurtosis \\
\hline Female Adolescents & 105.89 & 108.00 & 20.42 & 0.02 & -0.51 \\
\hline
\end{tabular}

The variable of Emotional Maturity among female adolescents was tested for normalcy. Table 2 shows that the values of mean and median of the female scores of adolescents on the variable of Emotional Maturity as 105.89 and 108.00 respectively which are quite proximate to each other. The values of skewness and kurtosis in case of female adolescents are 0.02 and -0.51 respectively showing the distribution as positively skewed and platykurtic. But these distortions are quite small. Therefore the distributions can be taken as normal.

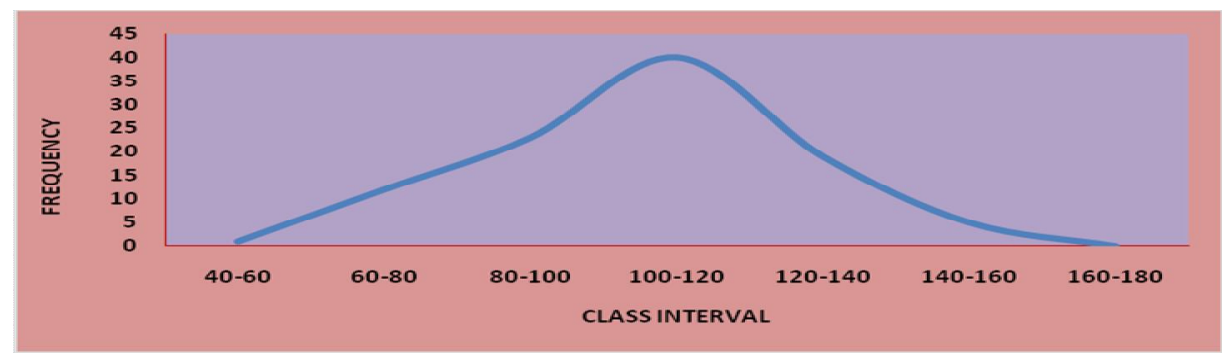

Figure 2. Frequency Polygon of Scores of Female Adolescents on the variable of Emotional Maturity $(\mathbf{N}=100)$

Table 3. Difference between Mean Scores of Emotional Maturity among Male and Female Adolescents ( $\mathbf{N}=200)$

\begin{tabular}{|c|c|c|c|c|c|c|c|}
\hline Group & Variable & $\mathbf{N}$ & $\mathbf{M}$ & S.D & $\mathbf{S E}_{\mathbf{M}}$ & $\begin{array}{r}\mathbf{t} \\
\text { ratio }\end{array}$ & Sig./Not Sig. \\
\cline { 1 - 5 } Male & Emotional & 100 & 106.96 & 20.49 & 2.05 & \multirow{2}{*}{0.37} & Not Sig. \\
\cline { 1 - 4 } Female & Maturity & 100 & 105.89 & 20.42 & 2.04 & & \\
\hline
\end{tabular}

Table 3 revealed that the mean scores of the variable of Emotional Maturity of male and female adolescents is 106.96 and 105.89 respectively. The t-ratio is calculated as 0.37 with $\mathrm{d}_{\mathrm{f}}=198$ which is not significant at 0.05 level of confidence. This revealed that no significant difference exists between mean scores of the variable of Emotional Maturity of male and female adolescents. 


\section{Journal of Exercise Science \& Physiotherapy Vol. 15 No. 1 (January to June) 2019}

ISSN: 0973-2020 (Print) $\quad \mathrm{I}_{2} \mathrm{OR}$ Impact Factor $=6.502 \quad$ ISSN: 2454-6089 (Online)

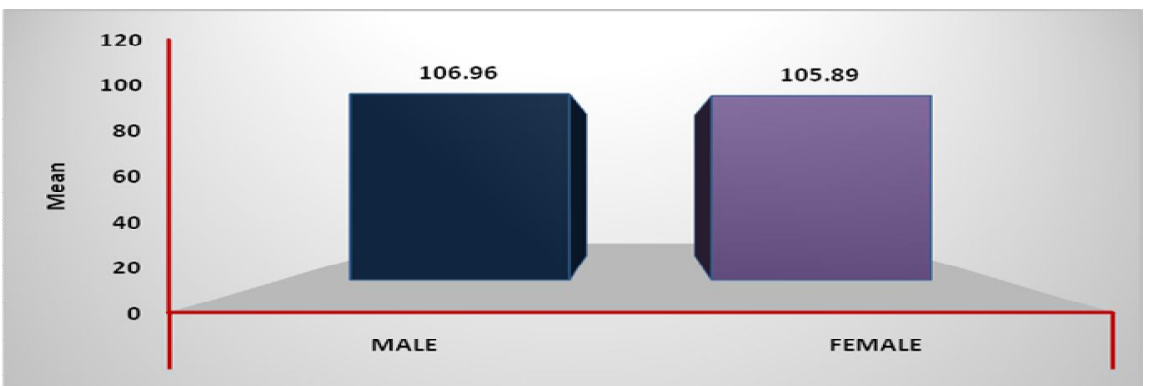

Figure 3. Difference between Mean Scores of Emotional Maturity among Male and Female Adolescents $(\mathbf{N}=\mathbf{2 0 0})$

\section{Conclusion}

It was concluded that there was no significant difference exists between mean scores of the variable of Emotional Maturity of male and female adolescents. This indicates that gender does not play a significant role in determining the Emotional Maturity among adolescents.

\section{References}

Anand, A.K., Kunwar, N. and Kumar, A.2014. Impact of different factors on Emotional Maturity of Adolescents of coeducational school. International Research Journal of Social Sciences. Vol. 3, Issue 11, 17-19.

Duhan, K., Punia, A. and Jeet, P.2017.Emotional maturity of adolescents in relation to their gender. International Journal of Educational Science and Research. Vol. 7 Issue 1, 61-68.

Dutta, J. \& Chetia, P. 2014. A Comparative Study of Emotional Maturity of Secondary School Students in Districts of Assam. International Journal of Science and Research Vol.4, 168-172.

Gunasekar, N. and Pugalenthi, N.2015. Study on emotional maturity and academic achievement at secondary level. Shanlax International Journal of Education, Vol. 3, issue 4, 7-13.

Seoul, L.J.1951..Emotional Maturity The development and dynamics of Personality. London:J.B.Lippincott.

Singh, Y. and Bhargava, M. 1999. Manual for Emotional Maturity Scale. National Psychological Corporation.

Walter,DandSmitson,W.S(1974).The meaning of Emotional Maturity,M.H. Winter.58:9-11. 